\title{
Configurations of Low-contact Services
}

\author{
Rohit Verma \\ Department of Management, DePaul University, Chicago, IL 60604, USA \\ Scott T. Young \\ David Eccles School of Business, University of Utah, Salt Lake City, UT 84112, USA
}

\begin{abstract}
This study uses a cluster analysis procedure to develop a classification model of low-contact services based on seven operations objectives. The effectiveness of the classification scheme is tested by demonstrating the link between the objectives, competitive priorities, and performance. This study also identifies eight underlying factors of competitive priorities in low-contact services. Furthermore, discriminant analysis on competitive priority dimensions shows that low-contact services consist of multiple groups and therefore should not be lumped into one group in any analysis scheme.
\end{abstract}

\section{Introduction}

Services continue to increase in importance as the postindustrial economy evolves in the developed nations around the world (Chase, 1978, 1981; Schmenner, 1986; Wemmerlov, 1990; Silvestro et al., 1992; Kellogg and Nie, 1995). Both academic and practitioner literature cite low-contact services as being efficient (similar to assembly lines in manufacturing) and capable of producing service products at very high productivity levels (e.g. Bowen and Youngdahl, 1998). Although low-contact services exist in many different industries, e.g. fastfood, dry cleaning, and automobile repair, the literature often treats them as a single homogeneous group. Also, most of the low-contact services are assumed to be efficient, productive and/or profitable. In this paper, we demonstrate that low-contact services are, in fact, comprised of multiple groups, with different operational objectives, competitive priorities and performance.

The motivation for our work stems from two streams of research. First, a number of articles have argued that service management research has moved beyond the primary classification stage and therefore, it is now necessary to validate the generally accepted concepts/frameworks (Meredith et al., 1989; Flynn et al., 1990; Swamidass, 1991; Chase, 1996). For example, recently, Kellogg and Chase (1995) empirically identified the three dimensions of customer contact: contact time, intimacy, and, information. Similarly, Silvestro et al. (1992) gathered in-depth data from 11 service organizations and identified firms as people-focused, people/equipment-focused and equipment-focused. More recently, teams of international 
researchers have started collecting large-scale empirical data from senior executives from service firms in Europe and the Unites States to identify the characteristics of "world-class" service firms (Voss and Johnston, 1995; Roth et al., 1997). Along similar lines, our work focuses on the in-depth analysis of low-contact service operations.

The second motivation for this research comes from a series of recent articles which argues that in order to effectively compete in a competitive marketplace, service companies must develop a coherent operations strategy (Vickery et al., 1993, 1997; Ahmad et al., 1996). For example, Smith and Reece (1999) presented a path analysis model linking service strategy, fit, productivity and performance for individual branches of a large organization. Our study demonstrates the linkages between objectives, competitive priorities, and relative performance within segments of low-contact services.

The rest of the manuscript is divided into the following sections. First, we review the past research and develop research questions. Next, we describe the research design, present the results and discuss the findings, and finally, we conclude and provide directions for future research.

\section{Background and Research Questions}

\section{Service Typologies and Taxonomies}

This section offers a review of various service classification approaches, as well as a discussion of their relative strengths and weaknesses. This review is provided in order to illustrate that while a variety of insightful conceptual typologies have been developed, there is a need to provide empirical validation in order to identify whether these typologies accurately model reality, as well as identify any shortcomings. The readers can refer to a recent article by Bozarth and McDermott (1998) for an overview of manufacturing typologies/taxonomies.

In one of the early classifications, Judd (1964) classified services according to three categories: rented goods, owned goods and non-goods services. Similarly, Rathmall (1974) categorized services according to: type of buyer, buyer motives, buying practices, type of seller, and degree of regulation. Other classification schemes explored the complex nature of service delivery systems with the goal of identifying differentiating characteristics that affect quality and process improvement, as well as service design. For example, Shostack (1977) and Sasser et al. (1978) developed the concept of "product-service package" based on the tangible vs. intangible nature of services.

More recent researchers advocated an integrated approach to service management. For example, Lovelock (1983) classifies services in five different two-by-two matrices and examines how the specific nature of services in a particular class affects operations and marketing. The framework of Lovelock (1983) addresses the following: the nature of service act; the type of relationship between service organization and its customers; customization; the nature of demand and supply; and service delivery process. 
Chase $(1978,1981)$ proposed that if there is less direct customer contact in the service system, then the service system is more likely to operate at its peak efficiency. Conversely, the system is less likely to operate at its peak potential with high direct customer contact. Mersha (1990) proposed a broadened definition of customer contact and differentiated between active and passive contact.

Building on the customer contact model of Chase $(1978,1981)$, Schmenner (1986) proposed a Service Process Matrix (SPM) based on three characteristics of service delivery systems: labor intensity, customer contact and service customization. Labor intensity is defined as the ratio of the labor cost incurred to the value of the plant and equipment. A high labor intensity business involves relatively small plant and equipment investment relative to a considerable amount of worker time, effort, and cost. The second dimension in the classification scheme combines two distinct concepts: customer interaction and customization. The joint measure has a high value when a service exhibits both a high level of interaction and a high level of customization for the customers. Schmenner (1986) proposed a two-by-two SPM that classifies services as service factory, service shop, mass service, and professional service.

Since the publication of Schmenner's (1986) SPM, several other service classification matrices have been developed. For example, Wemmerlov (1990) classified services along three dimensions: customer contact, rigid vs. fluid service process, and processing of goods, information or people. Huete and Roth (1988) classified banking services according to delivery channels. Silvestro et al. (1992) classified services as: professional service, service shop, and mass services, based on high/low people content and high/low numbers of customers processed. Kellogg and Nie's (1995) SP/SP matrix is based on the nature of service products, and service processes classify services as expert service, service shop, and service factory.

The classification approaches described above are based on unique attributes of services such as customer contact, customization, labor intensity, people vs. equipment issues, etc. Although these publications provide theoretical basis for analyzing different types of services, they all fail to recognize the differences within service businesses in a specific category (e.g. low-contact service, service factory, professional service, etc.). For example, according to SPM (Schmenner, 1986), all airlines, trucking, and hotels are service factories; all hospitals and repair services are service shops; all retail businesses are mass service; whereas all doctors, lawyers, accountants and architects are professional service providers. Similarly, according to the SP/SP matrix (Kellogg and Nie, 1995), all fastfood restaurants are classified as service factory, all health care clinics as service shop, and all consultings as expert service. Other service classification approaches (e.g. Lovelock, 1983; Wemmerlov, 1990; Silvestro et al., 1992) make similar generalizations.

Our research specifically deals with low-contact services. We explore the differences within two prototype low-contact services - fastfood and automobile repair services. We argue that it is unrealistic to assume that all low-contact services are configured in the similar manner and that they all emphasize same issues. Developing a finer-grained classification that 
can separate different strategies/approaches within larger macrocategories (e.g. low-contact services) allows more detailed insights and guidance. Therefore, we propose:

Hypothesis 1. Low-contact services are comprised pf multiple groups, each with different operating characteristics.

Section 2.2 of the paper describes the past research in service strategy, specifically focusing on operational objectives, competitive priorities, and performance measure.

\section{Operational Objectives, Competitive Priorities and Performance}

In one of the early works in operations strategy, Hayes and Wheelwright (1984) identified four market-based performance measures for manufacturing and service operations. Cost was identified as the first competitive dimension, but is not the only basis on which a business can compete. In some businesses, the basis of a competitive advantage is superior product or service quality. Delivery performance and flexibility were identified as the third and the fourth competitive dimensions, respectively. The above measures of operational objectives have been talked about in the operations strategy literature since the early days of the discipline and therefore require no further explanation. Ferdows and Meyer (1990) developed a "sand cone model" and concluded that it is extremely difficult for companies to achieve excellence in all four objectives at the same time. They recommended a gradual approach excelling in one competitive objective before attempting to improve the next one. In recent studies, however, Flynn and Flynn_1999., and Flynn et al. (1999) argue that it is possible for firms to strategically position themselves in a manner such that several operational objectives are achieved simultaneously.

According to the "production line" approach put forth in the early works of Levitt (1972, 1976), cost should be the most important objective for the service factories. In the customer contact model (Chase, 1978, 1981), it is argued that since low-contact services (i.e. service factories) are designed to maximize efficiency, the most important operational objective is cost minimization. Increased competition and the market-driven nature require all services (including service factories) to constantly upgrade their quality, delivery and flexibility performance. Heskett's (1987) "strategic service vision", Hart's (1988) "unconditional service guarantee", and Reichheld and Sasser's (1990) "zero defections" are some of the alternative approaches for thinking about operational objectives in service factories. In addition, the service marketing literature emphasizes that operations objectives should include market- and financial-based measures (Kordupleski et al., 1993; Karmarkar and Pitbladdo, 1995; Rust et al., 1995). At the same time, it is perhaps not an oversimplification to state that there is no agreement on how operational objectives should be prioritized in service factories. It is possible that certain companies only emphasize one or two objectives, while others try to achieve several objectives at the same time. Based on the above ideas, we develop the following research hypothesis: 
Hypothesis 2. Low-contact services can be classified into distinct groups based on the relative importance allocated to operational (cost, quality, delivery, flexibility), market and financial objectives.

Operations strategy, defined as the collective pattern of decision-making, is reflected by a firm's structural, infrastructural decisions and competitive priorities (Anderson et al., 1989; Vickery et al), 1993; Boyer et al., 1996.. Development of a coherent operations strategy includes translating chosen operational objectives into specific competitive priorities and ensuring that each member of an organization understands them with a reasonable amount of certainty. Although competitive priorities for various types of manufacturing operations have been studied in numerous studies, relatively nothing has been done to identify and to explore the relationship between competitive priorities and other operational issues in low-contact services.

Building on past work in operations strategy, we have conceptualized competitive priorities in low-contact services as specific policies/actions which management can emphasize to achieve the chosen operational objectives. In other words, the chosen objectives subsequently lead to specific competitive priorities. For example, if a company's main operational objective is to improve service quality, then it would tend to prioritize the determinants of service quality (such as reliability, tangibles, responsiveness, etc.). Similarly, if a firm's main operational objective is to improve flexibility, then they would tend to prioritize the determinants of flexibility, such as variety, and volume flexibility. In other words, differences in operations objectives should determine the relative weight assigned to different competitive priorities.

Hypothesis 3. Low-contact service groups differ from each other in terms of their competitive priorities.

A number of recent articles in operations strategy literature have demonstrated the link between operational competitive priorities and various performance measures. For example, in a recent study, Smith and Reece (1999) developed a causal model linking various service strategies, productivity and business performance measures. Similarly, Bozarth and Edwards (1997) demonstrated the link between market focus, manufacturing strategy, and performance at the plant level. In another recent study, Pullman and Moore (1999) developed an optimal service design approach which was based on customer preferences and operational characteristics and linked with market performance. In early conceptual work, both Davidow and Uttal (1989) and Heskett (1987) also strongly advocated the strong link between service strategy and performance.

Although the link between service operations strategy, priorities, and performance has been studied recently (e.g. Smith and Reece, 1999), there has been no systematic research in exploring the differences between performance measures of different service groups. Building on the past work of Boyer et al. (1996) and Miller and Roth (1994) in manufacturing industries, 
OPERATIONS STRATEGY

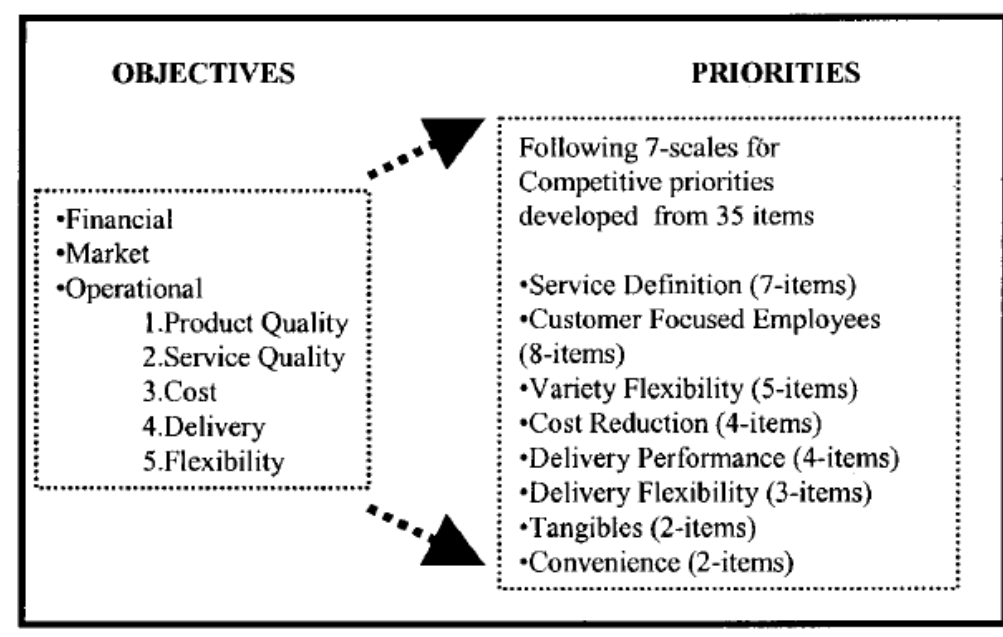

Cluster Analysis

Analysis of Variance
Exploratory Factor Analysis

Analysis of Variance

Discriminant Analysis
PERFORMANCE

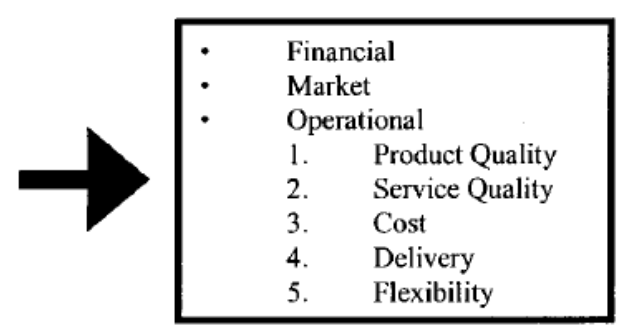

Analysis of Variance

Fig. 1. Conceptual framework and analysis methodology.

we propose that firms in different service clusters cannot not have similar performance because their objectives and corresponding competitive priorities are not the same. Most of the articles cited above measure quality, cost, delivery and flexibility performance. We have chosen to add financial and market performance as suggested by a number of recent articles (Kordupleski et al., 1993; Karmarkar and Pitbladdo, 1995; Rust et al., 1995; Pullman and Moore, 1999). Therefore:

Hypothesis 4. Low-contact service groups differ from each other in terms of their operational (quality, cost, delivery, flexibility), market, and financial performance measures.

The conceptual framework behind our work is summarized in Fig. 1. The broader operations strategy construct is subdivided into objectives and competitive priorities. As hypothesized earlier, we expect that low-contact services can be classified in subgroups based on their objectives (Hypotheses 1 and 2) and will differ from each other in terms of their competitive priorities (Hypothesis 3 ). We also hypothesized that business performance for service clusters will differ from each other (Hypothesis 4).

\section{Research Methods}

\section{$\underline{\text { Data Collection }}$}

Empirical data for this study were collected from the operations managers of fastfood and automotive repair establishments in a large metropolitan area located in the western United States. We chose to study these two industries because they represent services with 
minimum customer contact and relatively low customization and therefore can be considered prototype low-contact services (e.g. Schmen- ner 1986; Kellogg and Nie 1995). First, informal interviews with five managers in each of the two industries were conducted followed by a pilot study data collection from 10 more managers of each industry. The survey instrument was updated and refined after the pilot study.

Finally, 125 fastfood and 175 auto repair establishments were randomly selected from the local telephone directory, representing half of the local population of each service type. The survey instrument and a forwarding letter from the lead researcher were hand-delivered to the manager of each selected service establishment. Approximately two-thirds of the managers agreed to respond to the survey instrument immediately. The rest either refused to participate in the study (primarily because of time constraints) or asked the research assistants to return later. A total of 251 surveys were returned, with the effective response rate of $83.67 \%$. It should be noted that the response rate for this study was considerably higher than that of typical mail surveys because we personally contacted the managers (the response rates are generally less than $40 \%$ for mail surveys).

\section{Survey Instrument}

The questionnaire contained four broad types of questions. The first section asked the managers to rate the operational objectives of their establishments on a seven-point scale $(1=$ not important; 4 = average importance; 7 = most important). The second section contained a series of questions measuring competitive priorities on seven-point scale. The third section asked the managers to rate their relative quality, cost, delivery, flexibility, market, and financial performance, also on seven-point scale. Section four contained standard demographic questions (age, work experience, gender, and education level).

The sections on operational objectives and performance each contained seven questions related to financial, market, cost, delivery, product quality, service quality, and flexibility. As mentioned earlier, building on recent publications, and based on qualitative data collection from managers, we decided to add two questions related to financial and market performance. The managers identified both financial and market performance as valid and important operational objectives and performance measures. Other recent studies have also used sales and market share growth as performance measures (Miller and Roth, 1994; Boyer et al., 1996).

The competitive priorities were measured by 40 items generated from a list of questions used in previous studies (e.g. Vickery et al., 1993; Miller and Roth, 1994). These questions exploded product quality, service quality, cost, delivery, and flexibility objectives into their primary determinants. For example, product quality can be achieved by enhancing one or more of the following determinants (Garvin, 1987): performance, features, conformance, reliability, durability, serviceability, aesthetics, or perceived quality. Similarly service quality can be enhanced by prioritizing one or more of the following determinates identified by Parasuraman 
et al. (1985): reliability, responsiveness, competence, access, courtesy, communication, credibility, security, understanding/ knowing the customer, and tangibles. Similarly, flexibility can be achieved by increasing the product/ service mix and/or by new product/service development efforts. Multiple items were constructed (similar to the 22-item SERVQUAL instrument) to measure each construct. The results section of this paper includes a list of items, which is consistent with Miller and Roth (1994), and a series of articles on operations strategy published by Vickery et al. (1993, 1997).

\section{Data Analysis}

The data analysis for this study involved the following steps. To test Hypothesis 1 , we used hierarchical cluster analysis on operational objectives as perceived by the managers. Second, we examined the taxonomy by testing Hypotheses 2 and 3. Specifically, we demonstrate that competitive priorities for the identified service factory groups were different from each other using one-way ANOVA on competitive priority factors (since the competitive priorities were measured by 40 items, we first used exploratory factor analysis to identify the underlying factors). Next, we used discriminant analysis on competitive priorities to demonstrate the effectiveness of the identified service factory classification scheme. Finally, we used one-way ANOVA to test if performances for the identified service factory groups were different from each other.

\section{Results and Analysis}

\section{$\underline{\text { Respondents' Profile }}$}

Table 1 presents the summarized background information about the respondents. The average age for the respondents was 33.7 years; approximately $82 \%$ was male; average work experience in the current firm was 7 years; and average additional work experience was 7.5 years. Approximately two-thirds of the respondents was educated beyond the high school degree, but slightly less that $10 \%$ had a four-year college degree. Given the nature of lowcontact services and the relatively low wage structure, the above demographics about education level should not be surprising. There are slight differences between the demographic profiles of the respondents from the fastfood and the auto repair industries. On average, the auto repair managers were slightly older (35 vs. 31 years), had more work experience, and were mostly male (over $90 \%$ of the respondents).

\section{Service Clusters}

As mentioned earlier, low-contact services are often classified within a single category (e.g. Chase, 1978). We also mentioned that there is no apparent agreement on how service factories should prioritize their operational objectives. To explore the above issues and test Hypothesis 1, we conducted a hierarchical cluster analysis using Ward's method. Similar approaches have been used in the recent operations management articles. For example, Miller and Roth (1994) used such an approach to develop a taxonomy of manufacturing strategies. 
Table 1

Respondents' profile

\begin{tabular}{|c|c|c|c|}
\hline & Fastfood & Auto repair & All respondents \\
\hline Average work experience in the current firm & 5.26 years & 8.70 years & 7.52 years \\
\hline Average additional work experience & 4.48 years & 6.51 years & 7.01 years \\
\hline \multicolumn{4}{|l|}{ Education (\%) } \\
\hline Less than high school & 1.0 & 4.7 & 4.4 \\
\hline High school & 20.2 & 32.2 & 27.1 \\
\hline 1 Year college completed & 17.2 & 16.8 & 16.7 \\
\hline 2 Years in college/associate degree completed & 21.2 & 22.8 & 21.9 \\
\hline 3 Years in college completed & 15.2 & 6.7 & 10.0 \\
\hline 4-Year college degree completed & 13.1 & 10.1 & 11.2 \\
\hline Postgraduate degree & 12.1 & 6.7 & 8.8 \\
\hline Average age & 31.45 years & 35.15 years & 33.67 years \\
\hline$\%$ Female & $33 \%$ & $8.6 \%$ & $18.3 \%$ \\
\hline Sample size & 100 & 151 & 251 \\
\hline
\end{tabular}

Similarly, Boyer et al. (1996) identified the patterns of investment in advanced manufacturing technologies using hierarchical cluster analysis. However, to our knowledge, this approach has not been used to develop any service taxonomies.

As mentioned by Boyer et al. (1996) and Miller and Roth (1994), the primary challenge associated with cluster analysis methodology is the issue of determining the appropriate number of clusters. Boyer et al. (1996) recommend making a balanced choice between parsimony (few clusters) and accuracy. Along these lines, Lehmann (1979) recommends that the final number of clusters should be between $n / 30$ and $n / 60$, where $n$ represents the sample size. After the identification of the clusters, a one-way ANOVA is conducted to assess the differences across the groups. Scheffe's pairwise comparison procedure is used to test for differences between individual pairs of groups if one-way ANOVA results are statistically significant.

Table 2 presents the summarized results of the cluster analysis performed on the seven operations objectives described earlier. We chose to stop further classification after developing a five-cluster model because the sample size for one cluster dropped to single digit. Each group in the five-cluster model presented in Table 2 represents an approach towards setting up broad operational objectives. One-way ANOVA results for each operations objective were statistically significant at $p=0.05$ (to ensure consistently high statistical power level, $p=0.05$ was used for all the analyses presented in this paper as recommended by Verma and Goodale, 1995). Additionally, the follow up Scheffe's pairwise comparison results demonstrated that operations objectives for each cluster were different from, at least, two other identified clusters. Together, these results supported Hypothesis 1, which states that low-contact services can be classified according to their operations objectives.

Approximately $20 \%$ of the firms was classified in Cluster 1 which we have labeled as Financial Gain Seekers. For this group of low-contact services, financial gains seem to be the most important objective, followed by service quality enhancement and cost reduction. Market 


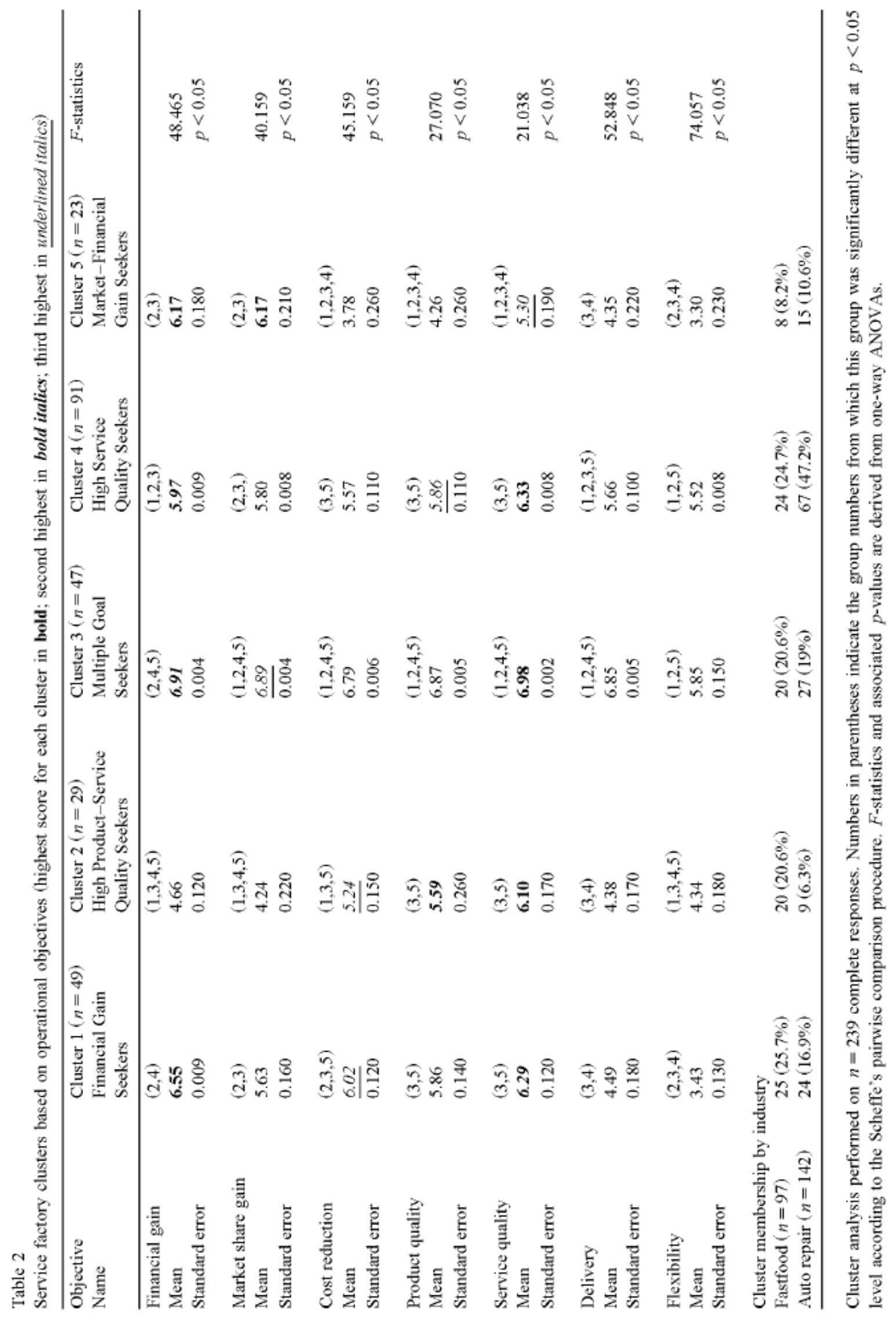


share gain and product quality improvement scores are also high. However, delivery and flexibility scores were very low for this group. Hence, it can be concluded that the focus of Cluster 1 firms was on enhancing their monetary position.

Cluster 2 firms (High Product-Service Quality Seekers), on the other hand, prioritized service quality and product quality improvement. The relative scores for financial and market share objectives were much lower than those of Financial Gain Seekers. Approximately 12\% of service factories fell in this category. It is also interesting to note that while High ProductService Quality Seekers do not emphasize financial and market objectives, cost reduction was identified as the third most important objective. The relative magnitudes for delivery (4.38) and flexibility (4.34) objectives were similar in importance to financial (4.66) and market share (4.24) gain.

Twenty percent of firms was classified in Cluster 3 (Multiple Goals Seekers). These firms gave very high scores (5.85 or higher) to all seven objectives. Therefore, it can be concluded that Cluster 3 firms wished to achieve multiple (or all) objectives simultaneously and they did not have a clearly defined operational priority.

Cluster 4 (High Service Quality Seekers) contained the largest number of firms (38\%). The most important operations objective was service quality followed by financial gain. Relative scores for other objectives were also high compared to Financial Gain Seekers and High Product-Service Quality Seekers, but were lower than Multiple Goal Seeker firms. Approximately $10 \%$ of firms fell in Cluster 5 (Market-Financial Gain Seekers) and they seemed to emphasize financial and market share gain over the other operations objectives.

A cross-tabulation of cluster membership and industry type is included in Table 2 to demonstrate that the fastfood and auto repair respondents are distributed throughout the five clusters. The fastfood firms are almost evenly distributed in Clusters 1-4 (25.7\%, 20.6\%, 20.6\%, 24.7\%), whereas $47.2 \%$ of auto repair firms was classified as High Service Quality Seekers (Cluster 4). These results further support our research objectives that service firms should not be classified solely on the basis of industry type.

The cluster analysis results presented above clearly illustrate that the five groups emphasized operational objectives differently and therefore support Hypotheses 1 and 2 . Therefore, we continue with the data analyses to test Hypotheses 3 and 4 and to demonstrate the link between objectives, competitive priorities, and performance.

\section{Competitive Priorities}

\section{Scale Development}

The survey instrument contained 40 items related to various competitive priorities (Vickrey et al., 1993, 1997; Miller and Roth, 1994). These competitive priority measures provide finer-grained, more specific information than the objectives measures in Section 4.2. However, several of these items might represent identical or similar constructs. Additionally, underlying 
competitive priority dimensions have not been specifically identified for the low-contact services. Therefore, we used Principle Components Analysis (exploratory factor analysis) to develop reliable multiple-item measures for each of the underlying theoretical constructs (Johnson and Wichern, 1988; Hair et al., 1998).

Eight eigenvalues exceeded the generally accepted cutoff value of 1.0 and were therefore retained in the further data analysis. It should also be noted that the eigenvalues for 9 th, 10th and 11 th factors not retained in the analyses were $0.88,0.80$, and 0.75 , which were much lower than the cutoff point value of 1.0. Together, the eight retained factors explained approximately $58 \%$ of the variance in the data. In order to increase the interpretability, a Varimax rotation was performed on the identified principle components. Items were then assigned to the factor on which they had the highest loadings. Only items, which had loadings of at least 0.4 on at least one factor, were retained in the analysis. We also eliminated the items that loaded on multiple factors. Using the above guidelines, a total of 36 items were retained in the analysis as measures for eight competitive priority dimensions. Table 3 presents the Varimax rotated principle components analysis results. For the sake of clarity, rotated factor scores lower than 0.4 are not shown in Table 4.

We have labeled each of the eight factors shown in Table 3 according to the items, which loaded on that latent competitive priority dimension. The customer-focused employee is comprised of eight items related to employee knowledge/skills, trustworthiness, promptness and the manner in which they provide service to the customers. The second factor labeled as service definition is comprised of seven items, all of which try to define the service for the customers. The variety flexibility factor measures the breadth of product and service package delivered to the consumers. Four items related to reduction of operating cost loaded on the fourth factor. Similarly, four other items related to delivery performance loaded on the fifth factor. We have labeled the sixth factor as delivery flexibility and it measures the firm's ability to provide the service when/how the customer wants. The final two factors are tangibles and convenience and are comprised of two items each.

\section{$\underline{\text { Scale Reliability Assessment }}$}

Since the competitive priority scales developed via factor analysis are new for lowcontact services and have not been validated in previous studies, we must take care to assess the inter-item reliability of the items comprising each scale (Flynn et al., 1990). Cronbach's coefficient alpha was used to assess inter-item reliability, with alpha values of 0.70 or higher considered to indicate acceptable reliability for established scales and 0.60 being acceptable for new scales (Nunnally, 1978; Churchill, 1979). Therefore, we concluded that the competitive priority scales are comprised of reliable items.

Hypothesis 3 states that competitive priorities for low-contact services are based on their operations objectives. Therefore, we expect that service clusters, which differ from each other in terms of operations objectives, should exhibit different patterns of competitive 
Table 3

Factor analysis of competitive priorities (Varimax rotated factor scores)

\begin{tabular}{lllllllll}
\hline Factor name and items & Fac1 & Fac2 & Fac3 & Fac4 & Fac5 & Fac6 & Fac7 & Fac8 \\
Eigenvalue & 12.06 & 3.65 & 2.30 & 1.39 & 1.29 & 1.13 & 1.10 & 1.00 \\
Percent variance explained & 24.5 & 10.4 & 6.4 & 4.0 & 3.7 & 3.2 & 3.1 & 2.9 \\
\hline
\end{tabular}

Customer-focused employeer $(\alpha=0.8853)$

Employees' willingness to help customers $\quad 0.7461$

Reliable service $\quad 0.6947$

Knowledge/skills of employees contacting the customers $\quad 0.6940$

Trustworthy employees $\quad 0.6755$

Prompt service $\quad 0.6721$

Friendly and polite customer service personnel $\quad 0.6393$

Knowledge/skills of support personnel $\quad 0.6264$

Sympathetic and reassuring employees $\quad 0.6185$

Service definition $(\alpha=0.8877)$

Explaining the trade-off between service and cost to the customers $\quad 0.7665$

Explaining the cost of the service to the customers $\quad 0.7312$

Explaining the service to the customers $\quad 0.7104$

$\begin{array}{ll}\text { Serviceability of product } & 0.6719\end{array}$

Durability of product $\quad 0.6664$

Confidentiality of service $\quad 0.5848$

Financial security of the customer $\quad 0.5491$

Variety flexibility $(\alpha=0.9007)$

Being able to offer different type of products / services $\quad 0.8353$

$\begin{array}{ll}\text { Developing unique products/services } & 0.8281\end{array}$

$\begin{array}{ll}\text { Developing and providing innovative products/services } & 0.8081\end{array}$

$\begin{array}{ll}\text { Developing and introducing new products / services } & 0.7594\end{array}$

Developing a more complete line of services $\quad 0.7286$

Cost reduction $(\alpha=0.7852)$

Reducing operating cost by process improvement $\quad 0.7673$

$\begin{array}{ll}\text { Reducing operating cost by automation } & 0.7613\end{array}$

Reducing the net cost of product/service to the customer $\quad 0.5344$

$\begin{array}{lr}\text { Reducing operating cost by improving productivity } & 0.4588\end{array}$

Delivery performance $(\alpha=0.7964)$

$\begin{array}{ll}\text { Reducing lead time between order and service delivery } & 0.7627\end{array}$

$\begin{array}{ll}\text { Fast delivery } & 0.7236\end{array}$

$\begin{array}{ll}\text { Recognizing the regular customer } & 0,6149\end{array}$

$\begin{array}{ll}\text { Process improvement for better service quality } & 0.5014\end{array}$

Delivery flexibility $(\alpha=0.7279)$

$\begin{array}{lr}\text { Providing products/service how customer wants it } & 0.7508\end{array}$

$\begin{array}{lr}\text { Providing products/service when customer wants it } & 0.7410\end{array}$

$\begin{array}{lr}\text { Providing customer service when promised } & 0.5194\end{array}$

Tangibles

$\begin{array}{ll}\text { Appropriate physical appearance of the service facility } & 0.7889\end{array}$

$\begin{array}{lr}\text { Appearance of service personnel } & 0.7787\end{array}$

Convenience

Convenient location of service facility 0.7743

\begin{tabular}{ll} 
Convenient hours of operation & 0.7328 \\
\hline
\end{tabular}

Note: For the sake of clarity, factors score under 0.4 are not shown in the above table. Also note that the eigenvalues for the next three factors were $0.88,0.80$ and 0.75 . 


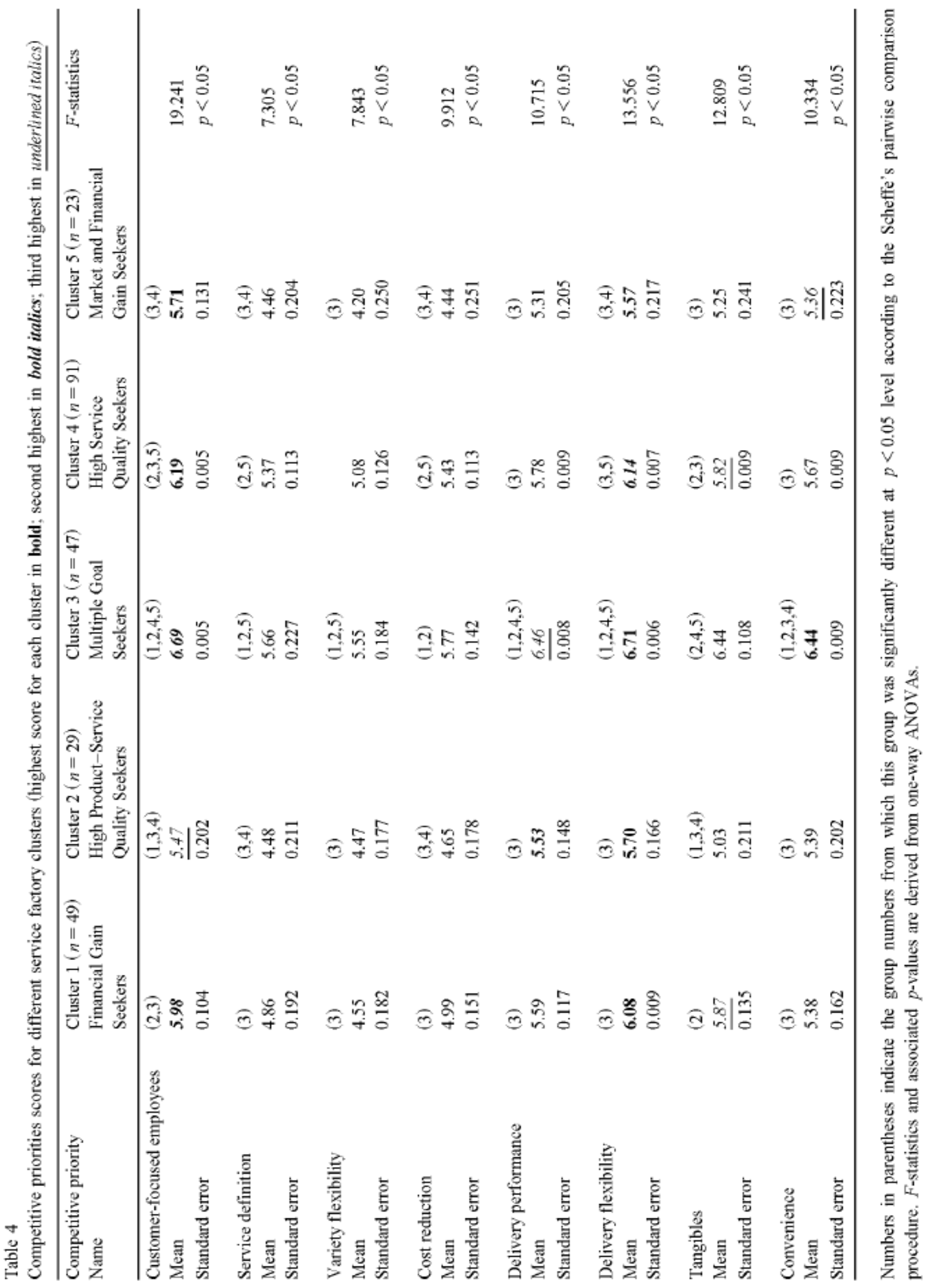


priorities. We tested the above hypothesis by two sets of statistical techniques. First, we used one-way ANOVA followed by Scheffe's pairwise comparisons to assess if the average scores are indeed different for each cluster for each identified competitive priorities factor (Table 4). We further tested the effectiveness of the service classification by conducting a discriminant analysis on the competitive priority factors. The discriminant analysis tested if the patterns of competitive priorities can correctly predict the original groups of the services, which were based on operations objectives.

One-way ANOVA results of competitive priorities dimensions are summarized in Table 4. The $p$-values for the F-tests were statistically significant at the $5 \%$ level for each of the eight competitive priorities dimensions. Furthermore, the follow up Scheffe's pairwise tests demonstrated that the average scores for most of the competitive priority dimensions were different for three or more clusters. These results support Hypothesis 3 and illustrate that, indeed, competitive priorities are dependent on operations objectives in low-contact services.

It is interesting to note that delivery flexibility and customer-focused employees were among the top two competitive priorities for all of the five service clusters. Additionally, the service definition, variety flexibility, and cost reduction were not among the top three priorities for any cluster. Other than the above similarities, the mean scores and their relative ranks for different priorities were completely different for the clusters shown in Table 4. Therefore, we concluded that competitive priorities are indeed based on operations objectives.

Next, a discriminant model was developed based on the eight competitive priority dimensions (independent variables) and by assuming that services were originally classified into five clusters (dependent variable). Miller and Roth (1994) used a similar approach to test the effectiveness of their taxonomy of manufacturing strategies. Table 5A shows the coefficients for each of the two discriminant functions, as well as Wilk's lambda and the mean scores for each of the five clusters (Hair et al., 1998).

As shown in Table 5A, both the discriminant functions were statistically significant based upon Wilk's lambda ( $p$ - 0.05). The coefficient for the customer-focused employees was the highest and substantially higher than the other coefficients in discriminant function 1 . On the other hand, discriminant function 2 was heavily weighted by the following four priorities: tangibles, convenience, delivery performance, and cost reduction. In addition, the group centroids (cluster means) for each of the five service factory clusters differed substantially. Discriminant function scores were standardized so that the entire sample had a mean of 0.00 and a standard deviation of 1.00. This allowed easy comparisons between the groups being classified. For example, the mean for Cluster 1 was in the third quadrant $(-0.21,-0.48)$; Cluster 2 mean was in the second quadrant $(-1.16,+0.51)$; Cluster 3 mean was in the first quadrant $(+1.06,+0.23)$; Cluster 4 mean was close to the origin in the fourth quadrant $(+0.169,10.002)$; and Cluster 5 mean $(-0.974,-0.004)$ was in third quadrant close to the axes of the first discriminant function. Fig. 2 shows the relative position of cluster means along the two discriminant axes. 
Table 5

Discriminant analysis results for competitive priorities

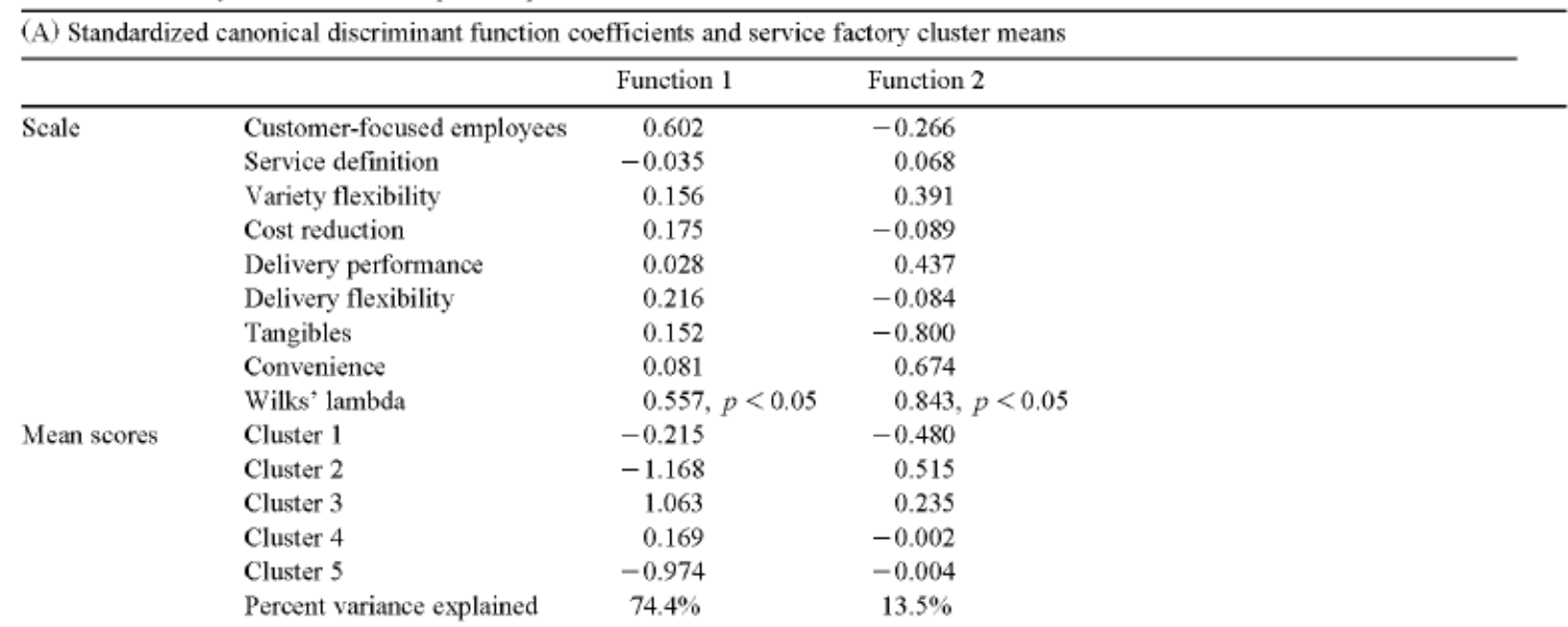

(B) Classification results for original cases overall accuracy ${ }^{\mathrm{a}}$ : $50.7 \%$; Press's $Q=82.6\left(\chi^{2}\right.$ with 1 df $), p<0.05$

\begin{tabular}{lllllll}
\hline Predicted group & Cluster 1 & Cluster 2 & Cluster 3 & Cluster 4 & Cluster 5 & Total \\
\hline Actual group & & & & & & \\
Cluster 1 & $\mathbf{7 ( 1 6 . 7 \% )}$ & $5(11.9 \%)$ & $3(7.1 \%)$ & $27(64.3 \%)$ & $0(0 \%)$ & 42 \\
Cluster 2 & $3(12 \%)$ & $\mathbf{1 0}(\mathbf{4 0} \%)$ & $3(12 \%)$ & $8(32 \%)$ & $1(4 \%)$ & 25 \\
Cluster 3 & $2(4.9 \%)$ & $0(0 \%)$ & $\mathbf{2 2}(\mathbf{5 3 . 7} \%)$ & $17(41.5 \%)$ & $0(0 \%)$ & 41 \\
Cluster 4 & $5(6.4 \%)$ & $1(1.3 \%)$ & $11(14.1 \%)$ & $\mathbf{6 0}(\mathbf{7 6 . 9} \%)$ & $1(1.3 \%)$ & 78 \\
Cluster 5 & $5(26.3 \%)$ & $4(21.1 \%)$ & $1(5.3 \%)$ & $4(21.1 \%)$ & $\mathbf{5 ( 2 6 . 3 \% )}$ & 19 \\
Total & 22 & 20 & 40 & 116 & 7 & $\mathbf{2 0 5}$
\end{tabular}

(C) Classification results for cross-validated cases overall accuracy ${ }^{3}: 43.4 \%$ : Press's $Q=44.4\left(\chi^{2}\right.$ with $\left.1 d f\right), p<0.05$

\begin{tabular}{|c|c|c|c|c|c|c|}
\hline Predicted group & Cluster 1 & Cluster 2 & Cluster 3 & Cluster 4 & Cluster 5 & Total \\
\hline \multicolumn{7}{|l|}{ Actual group } \\
\hline Cluster 1 & $6(14.3 \%)$ & $5(11.9 \%)$ & $3(7.1 \%)$ & $28(66.7 \%)$ & $0(0 \%)$ & 42 \\
\hline Cluster 2 & $3(12 \%)$ & $8(32 \%)$ & $3(12 \%)$ & $10(40 \%)$ & $1(4 \%)$ & 25 \\
\hline Cluster 3 & $3(7.3 \%)$ & $0(0 \%)$ & $18(43.9 \%)$ & $19(46.3 \%)$ & $1(2.4 \%)$ & 41 \\
\hline Cluster 4 & $7(9 \%)$ & $2(2.6 \%)$ & $12(15.4 \%)$ & $55(70.5 \%)$ & $2(2.6 \%)$ & 78 \\
\hline Cluster 5 & $6(31.6 \%)$ & $5(26.3 \%)$ & $1(5.3 \%)$ & $5(26.3 \%)$ & $2(10.5 \%)$ & 19 \\
\hline Total & 25 & 20 & 37 & 117 & 6 & 205 \\
\hline
\end{tabular}

${ }^{\mathrm{a}}$ Maximum chance criterion $=38 \%$, proportional chance criterion $=25 \%$.

Although it is extremely important to have statistically significant functions, it is also very important that the discriminant functions perform well in classifying service factories into their original groups for calibration and validation samples.

Table 5B presents the classification results based on the two discriminant functions shown in Table 5A for calibration sample. The rows of Table 5B show the actual classification (based on cluster analysis performed on operations objectives), while the columns show the predicted group based on the two discriminant functions. The companies in the main diagonal have correct predictions (shown in bold), while the other cells represent the misclassified firms.

If each cluster is comprised of equal number of responses, then without any additional prior information, one can randomly assign the services into the five groups with an expected probability of making a correct decision to be $20 \%$. In our case, the cluster sizes vary between 
23 and 91; therefore, a proportional chance criterion can be used to assess the predictive accuracy of a discriminant model (Morrison, 1969; Perreault et al., 1979; Huberty, 1984; Hair et al., 1998). The proportional chance criterion for a discriminant model can be defined as $\sum_{i=1, K}\left(p_{i}\right)^{2}$ where $p_{i}$ represents the expected probability that a randomly chosen observation will be classified in group $i$. The expected probabilities $\left(p_{i}\right)$ can be calculated by simply taking a ratio of number of observations/cluster with respect to total sample size. Since a total of 239 observations were retained in the discriminant analysis, the expected probabilities for the five clusters are $20.5 \%, 12.1 \%, 19.7 \%, 38.1 \%$ and $9.6 \%$, respectively. Therefore, the proportional chance criterion becomes $25 \%$. Hair et al. (1998) recommend that classification accuracy should be at least $25 \%$ higher than the proportional chance criterion for a good discriminant model $(1.25 \times 25 \%=31.25 \%)$. As shown in Table 5B, the classification accuracy for the estimated model was $50.7 \%$, which is considerably higher than the suggested guideline of Hair et al. (1998). Note that the classification accuracy of the estimated discriminant model is also higher than the maximum chance criterion (probability of being in the group with the largest sample size $=38 \%$ chance of being in Cluster 4) (Hair et al., 1998).

\section{Cluster Means}

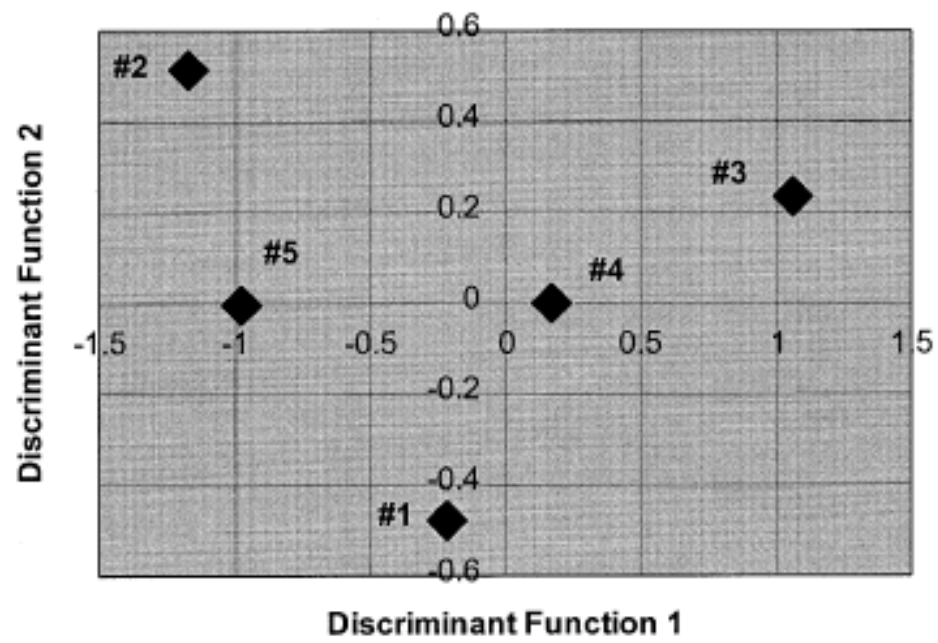

Fig. 2. Cluster means along the two discriminant axes.

The predictive accuracy of a discriminant model can be further verified by $\chi^{2}$ statistics $(d f=1)$ known as Press's $Q=[N-(n K)]^{2} /[N(K-1)]$ where $N$ represents total sample size, $n$ represents number of observations correctly classified, and $K$ represents number of groups. In our case, Press's $Q$ statistics was found to be $82.6 \%$, which is statistically significant at $\alpha=0.05$ and therefore supports the predictive accuracy achieved by the estimated discriminant model.

It is common practice to further validate the estimated discriminant models by either using a split sample (e.g. holdout sample) or a cross-validation technique (e.g. U-Method or Jackknifing). Although both approaches have been used in past research, leading statisticians 
favor cross-validation techniques over a split sample approach (e.g. Perreault et al., 1979; Hair et al., 1998) because cross-validation methods repeat the procedure multiple times. In crossvalidation, discriminant models are estimated by leaving one observation out and then the estimated models are used to predict the membership of the unselected observation. This process is repeated for each observation in the data set. Both U-Method and Jackknifing are based on the same principle. The primary difference is that U-Method focuses on classification accuracy, whereas Jackknifing focuses on the stability of discriminant functions. In our study, the purpose of discriminant analysis was to demonstrate the accuracy of classification and therefore, we used the U-Method to cross-validate the results. The results presented in Table $5 \mathrm{C}$ show that cross-validated cases are classified fairly accurately and exceed the proportional chance criterion, maximum chance criterion and are statistically significant based on Press's $Q$ statistics.

\section{$\underline{\text { Relative Business Performance }}$}

Since the operations objectives and competitive priorities are different for each of the five clusters, one would expect that the relative quality, cost, delivery, flexibility, market and financial performance of each cluster will be different. We proposed earlier (Hypothesis 3 ) that operation objectives determine competitive priorities and therefore should impact the performance of the service factories.

During the pilot data collection efforts, we realized that it would be extremely difficult to get accurate objective performance data from the operations managers. First, because of the confidential nature of this information, most managers contacted during the pilot study had simply refused to answer either the performance questions and/or the whole questionnaire. Second, because the individual service establishments are often part of large corporations, the performance data are often not available at the individual branch level. Therefore, the only data we could collect were the subjective measure of relative performance. On seven-point scales, managers evaluated their own performance with respect to close competitors. Although

subjective, such measures are common in operations strategy research because of the difficulty in obtaining the objective performance measures. For example, Boyer et al. (1996) measured sales growth, return on scales, and earnings growth on similar seven-point scales in a study of the investment patterns in advanced manufacturing technologies.

Table 6 presents the summarized performance results for each of the five service clusters. We conducted a series of one-way ANOVAs to test if the relative performances were different for each of the service factory groups. A-ratios for the seven performance measures (financial, market, cost, product quality, service quality, delivery, and flexibility) were statistically significant at the $5 \%$ level. Furthermore, the follow up Scheffe's pairwise comparisons showed that mean scores for a few clusters were different from each. Recognizing the limited information obtained from the performance data, we concluded that there is support for Hypothesis 3, which states that performance in service factories is based on 


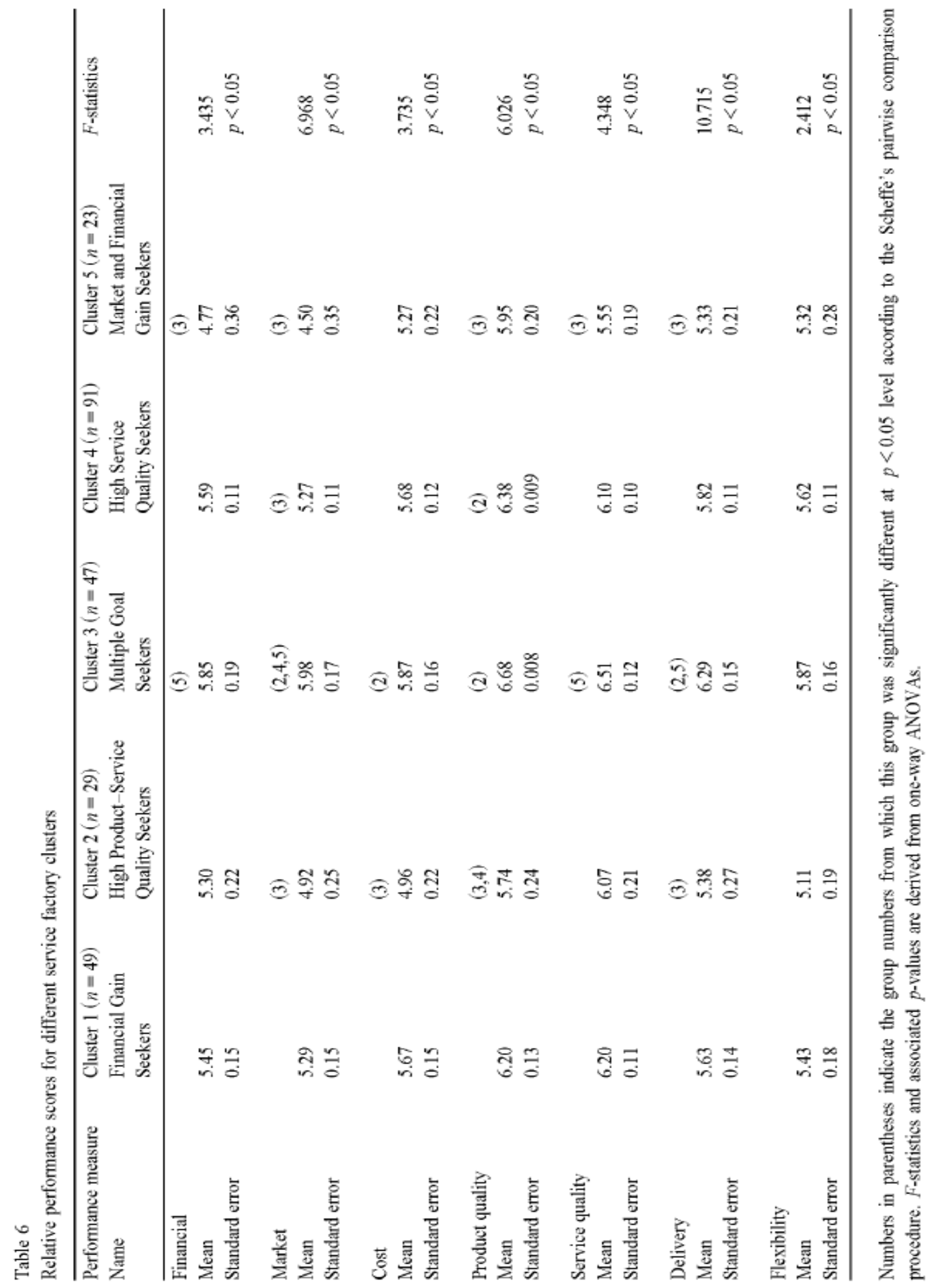


operations objectives and competitive priorities.

\section{Conclusions}

The objective of this research was to empirically assess the differences in operations objectives, competitive priorities and performance among the clusters of low-contact services. Data collected from the managers of two industries provide several interesting insights about the management of service factories.

Perhaps, the most important result presented in this paper is the fact that low-contact services appear to be comprised of multiple groups, which differ from each other in terms of their operational objectives, competitive priorities and performance. Based on these results, we conclude that it will be narve to consider all services within the same theoretical group in service classification schemes to be similar to each other. These results support the notion that service management researchers should move beyond the primary classification research and should now start testing the theories and concepts proposed in the past research. The results also suggest that practicing managers should not try to emulate other firms just because they are from the same industry. It is possible that two firms from same industry (e.g. fastfood) belong to different clusters, whereas two other firms from dissimilar industries (e.g. fastfood and auto repair) belong to the same cluster based on their objectives and corresponding competitive priorities. Therefore, the practicing managers should pay close attention to the characteristics of individual firms rather than making assumptions about the whole industry.

Identification of the competitive priority dimensions is another important finding of this study. The exploratory factor analysis results demonstrate that competitive priorities in lowcontact services are comprised of eight factors. The high factor loading and high reliability scores for the identified factors provide validity for the results presented earlier in this paper. The high scores also give service researchers confidence in using these scales in future researches for additional analysis and/or refinement.

The results of the discriminant analysis of competitive priorities serve to further validate the descriptive power of the cluster analysis performed on operations objectives. Even though the discriminant functions could only classify about $50 \%$ of the responses correctly, we consider the results to be very encouraging. The reader should note that these results are still over two times ( $25 \%$ vs. $50 \%$ ) better than random classification (proportional chance criterion). In addition, it should also be noted that we were trying to classify firms, which have always been considered to be one homogeneous group because they contain many similar attributes. Therefore, the classification task was inherently very difficult. Finally, we demonstrated that performance measures in different clusters are different from each other.

Although very encouraging, we consider our study to be only "exploratory" in nature. There are a number of limitations of our study, which should be addressed in future work. For example, our study was only based on two industries - fastfood mid auto repair. Future studies should try to expand the analysis to a larger number of low-contact services and data 
should be collected from a wider geographical region to insure generalizable results. Another limitation of this work is that we assumed that all the fastfood and auto repair establishments in the sample represent low-contact services. We did not measure customer contact directly. Future work should undertake some measure of customer contact and perhaps test specific propositions about objectives and competitive priorities assuming that customer contact might vary from firm to firm.

Overall, we believe that we have managed to address a number of relevant and important issues, which should be of interest to service management researchers and practitioners. We hope that other researchers will undertake similar research projects and attempt to test and validate existing service management theories. The role of empirical analysis is to test the extent to which theories fully represent reality and to suggest shortcomings, which lead to further research and refinement. Toward that end, further research should seek to add to the current findings by examining additional quantitative measures in an effort to develop a more accurate service classification model.

\section{Acknowledge}

The authors would like to thank the special issue editors, Chris McDermott, Ken Boyer, anonymous associate editor, and three anonymous reviews for providing many valuable comments during the review process.

\section{References}

Ahmad, N.U., Montagno, R.V., Firenze, R.J., 1996. Operations strategy and organizational performance: an empirical study. International Journal of Operations and Production Management 16 (5), 41-53.

Anderson, J.C., Cleveland, G., Schroeder, R.G., 1989. Operations strategy: a literature review. Journal of Operations Management 8 (2), 133-158.

Bowen, D.E., Youngdahl, W.E., 1998. "Lean" service: in defense of a production line approach. International Journal of Service Industry Management 9 (3), 207-225.

Boyer, K.K., Ward, P.T., Leong, K., 1996. Approaches to the factory of the future - an empirical taxonomy. Journal of Operations Management 14 (4), 297-312.

Bozarth, C., Edwards, S., 1997. The impact of market requirements focus and manufacturing characteristics focus on plant performance. Journal of Operations Management 15 (3), 161180.

Bozarth, C., McDermott, C., 1998. Configurations in manufacturing strategy: a review and directions for future research. Journal of Operations Management 16, 427-439. 
Chase, R.B., 1978. Where does the customer fit in a service operation. Harvard Business Review, November-December. Chase, R.B., 1981. The customer contact approach to services: theoretical bases and practical extensions. Operations Research 29 (4).

Chase, R.B., 1996. The mall is my factory: reflections of a service junkie. Production and Operations Management 5 (4), 298308, Winter.

Churchill, G.A., 1979. A paradigm for developing better measures of marketing constructs. Journal of Marketing Research 16 (2), 64-73.

Davidow, W.H., Uttal, B., 1989. Service companies: focus or falter. Harvard Business Review, July-August.

Ferdows, K., Meyer, A.D., 1990. Lasting improvements in manufacturing performance: in search for new theory. Journal of Operations Management 9, 168-184.

Flynn, B.B., Flynn, E.J., 1999. Achieving simultaneous competitive advantages through continuous improvement: world-class manufacturing as competitive strategy. Journal of Managerial Issues, forthcoming.

Flynn, B.B., Sakakibara, S., Schroeder, R.G., Bates, K.A., Flynn, E.J., 1990. Empirical research methods in operations management. Journal of Operations Management 9 (2), 250-284.

Flynn, B.B., Schroeder, R.G., Flynn, E.J., 1999. World-class manufacturing: an investigation of Hayes and Wheelwright's Foundation. Journal of Operations Management 17, 249-269.

Garvin, D.A., 1987. Competing on the eight dimensions of quality. Harvard Business Review, January.

Hair, J.F. Jr., Anderson, R.E., Tatham, R.L., Black, W.C., 1998. Multivariate Data Analysis. 5th edn. Prentice-Hall, New Jersey.

Hart, C.W.L., 1998. The Power of Unconditional Service Guarantees, Harvard Business Review, July-August.

Hayes, R.H., Wheelwright, S.C., 1984. Restoring Our Competitive Edge: Competing Through Manufacturing. Wiley, New York.

Heskett, J.L., 1987. Lessons in the service sector. Harvard Business Review, March-April.

Huberty, C.J., 1984. Issues in the use and interpretation of discriminant analysis. Psychological Bulletin 95, 156-171.

Huete, L.M., Roth, A.V., 1988. The industrialization and span of retail banks' delivery systems. International Journal of Operations and Production Management 8 (3), 46-66.

Johnson, R.A., Wichern, D.W., 1988. Applied Multivariate Statistical Analysis. 2nd edn. PrenticeHall, New Jersey. 
Judd, R.C., 1964. The case for redefining services. Journal of Marketing 28 (1).

Karmarkar, U.S., Pitbladdo, R., 1995. Service markets and competition. Journal of Operations Management 12, 397-411.

Kellogg, D.L., Chase, R.B., 1995. Constructing an empirically derived measure for customer contact. Management Science 41 (11), 1734-1749.

Kellogg, D.L., Nie, W., 1995. A framework for strategic service management. Journal of Operations Management 13, 323-338, December.

Kordupleski, R.E., Rust, R.T., Zahorik, A.J., 1993. Why improving quality doesn't improve quality (or whatever happened to marketing). California Management Review, 82-95, Spring.

Lehmann, D.R., 1979. Market Research and Analysis. Irwin, Homewood, IL.

Levitt, T., 1972. Production line approach to service. Harvard Business Review 50 (5), 20-31.

Levitt, T., 1976. The industrialization of service. Harvard Business Review 54 (5), 32-43.

Lovelock, C.H., 1983. Classifying services to gain strategic marketing insights. Journal of Marketing 47 (3), 9-20.

Meredith, J.R., Raturi, A., Amoako-Gyampah, K., Kaplan, B., 1989. Alternative research paradigms in operations. Journal of Operations Management 8 (4), 297-326.

Mersha, T., 1990. Enhancing the customer contact model. Journal of Operations Management 9 (3), 391-405.

Miller, J.G., Roth, A.V., 1994. A taxonomy of manufacturing strategies. Management Science 40 (3), 285-304.

Morrison, D.G., 1969. On the interpretation of discriminant analysis. Journal of Marketing Research 6 (2), 156-163.

Nunnally, J., 1978. Psychometric Theory. McGraw-Hill, New York.

Parasuraman, A., Zeithaml, V.A., Berry, L.L., 1985. A conceptual model of service quality and its implications for future research. Journal of Marketing 49, 41-50, Fall.

Perreault, W.D., Behrman, D.N., Armstrong, G.M., 1979. Alternative approaches for interpretation of multiple discriminant analysis in marketing research. Journal of Business Research 7, 151-173.

Pullman, M.E., Moore, W.E., 1999. Optimal service design: integrating marketing and operations perspectives. International Journal of Service Industry Management 10 (2), 239-260.

Rathmall, J.M., 1974. Marketing in the Service Sector. Winthrop, Cambridge, MA. 
Reichheld, R.F., Sasser, W.E. Jr., 1990. Zero defections: quality comes to services. Harvard Business Review, January.

Roth, A.V., Chase, R.B., Voss, C., 1997. Service in the US. A Study of Service Practices and Performances in the United States, Severn Trent, UK.

Rust, R.T., Zahorik, A.J., Keiningham, T.L., 1995. Return on quality (ROQ): making service quality financially accountable. Journal of Marketing 59, 58-70, April.

Sasser, E.E. Jr., Olsen, R.P., Wyckoff, D.D., 1978. Management of Service Operations: Text and Cases. Allyn and Bacon, Boston, MA.

Schmenner, R.W., 1986. How can service businesses survive and prosper. Sloan Management Review, 21-32, Spring.

Shostack, G.L., 1977. Breaking free from product marketing. Journal of Marketing 41 (4).

Silvestro, R., Fitzgerald, L., Johnston, R., Voss, C., 1992. Towards a classification of service processes. International Journal of Service Industry Management 3 (3), 62-75.

Smith, T.M., Reece, J.S., 1999. The relationship of strategy, fit, productivity, and business performance in a service setting. Journal of Operations Management 17, 145-161.

Swamidass, P.M., 1991. Empirical science: new frontier in operations management research. Academy of Management Review 16 (4), 793-814.

Verma, R., Goodale, J.C., 1995. Statistical power in operations management research. Journal of Operations Management 13 (2), 139-152.

Vickery, S.K., Drorge, C., Markland, R.E., 1993. Production competence and business strategy: do they affect business performance. Decision Sciences 24 (2), 435-455.

Vickery, S.K., Droge, C., Markland, R.E., 1997. Dimensions of manufacturing strength in the furniture industry. Journal of Operations Management 15, 317-330.

Voss, C., Johnston, R., 1995. Service in Britain: How Do We Measure Up? Severn Trent, UK.

Wemmerlov, U., 1990. A taxonomy for service processes and its implications for system design. The International Journal of Service Industry Management 1 (3), 13-27. 